\title{
Research on the Concept, Attribute and Systematization Construction of the Inner-Party Laws and Regulations
}

\author{
Xuguang Liu \\ Shanghai University of Political Science and Law, Shanghai, China \\ Email: 750345358@qq.com
}

How to cite this paper: Liu, X. G. (2021). Research on the Concept, Attribute and Systematization Construction of the Inner-Party Laws and Regulations. Open Journal of Social Sciences, 9, 134-148. https://doi.org/10.4236/jss.2021.95011

Received: April 14, 2021

Accepted: May 10, 2021

Published: May 13, 2021

Copyright (อ 2021 by author(s) and Scientific Research Publishing Inc. This work is licensed under the Creative Commons Attribution International License (CC BY 4.0).

http://creativecommons.org/licenses/by/4.0/

\section{(c) (i) Open Access}

\begin{abstract}
The inner-Party laws and regulations system is an important part of the system of socialist rule of law with Chinese characteristics. Realizing the rule of law in China, it is necessary to adhere to the rule of law construction of the CPC itself. Focusing on the lively practice of the construction of the inner-Party laws and regulations, this paper focuses on the dimensions of the standardization and conciseness of the concept of the inner-Party laws and regulations, the debate and clarity of internal attributes, the construction of institutional systematization, and the cohesion and coordination of the inner-Party laws and regulations and national laws. In-depth grasp of the concept and internal attributes of the inner-Party laws and regulations, through the effective realization of the cohesion and coordination of the inner-Party laws and regulations and national laws, continue to promote the system construction of the inner-Party laws and regulations. It can provide useful enlightenment for strengthening the construction of laws and regulations within the Communist Party of China in the new era, and also provide reference for the legalization of governance of the ruling parties in other countries in the world.
\end{abstract}

\section{Keywords}

The Communist Party of China, The Inner-Party Laws and Regulations, The Concept, The Attribute, Systematic Construction

\section{Introduction}

The inner-Party laws and regulations of the Communist Party of China is an important carrier for the Communist Party of China to manage the Party and realize the institutionalization, legalization and standardization of the Party's 
leadership. By exploring the lively practice of the construction of the inner-Party laws and regulations since the 18th National Congress of the Communist Party of China, both the basic theory and system practice of the inner-Party laws and regulations, we have made remarkable achievements and formed rich experiences. The research on the inner-party laws and regulations in Chinese academic circles began in the 1990s and rose in the first decade of this century. Since the 18th National Congress of the Communist Party of China, relevant research has developed rapidly and has shown explosive growth in the past three years. Due to the different academic backgrounds and research purposes of researchers, they can generally focus on Marxist theory, Party construction, Law, Political science and other fields, and the views generated are different. In terms of the essential attributes of inner-party laws and regulations, there is a debate about the "Soft law theory" of inner-party laws and regulations. For example, when discussing the special legal nature of inner-party laws and regulations of the Communist Party of China, Professor Jiang Ming'an analyzes the general characteristics of inner-party laws and regulations, and thinks that its basic position should belong to social law and soft law, rather than national law and hard law (Jiang, 2012). However, there are also many scholars who put forward distinct objections, the main point is that the theory of soft law within the party regulations have greater limitations ( $\mathrm{Wu}, 2016$; Xiao \& Feng, 2019). In addition, there are also many debates in the academic circle in terms of the attributes of inner-party laws and regulations, the cohesion and coordination between inner-party laws and regulations and national laws, and the systematic construction. In short, through the research on the theory and practice of inner-Party laws and regulations, it can provide useful enlightenment for the systematic and standardized construction of the inner-Party laws and regulations.

\section{Normative Concepts of the Inner-Party Laws and Regulations}

Since the 18th National Congress of the Communist Party of China, Xi Jinping has made a series of important discussions on the construction of the inner-Party laws and regulations. From the second plenary session of the 18th Central Commission for Discipline Inspection, it was emphasized that the construction of the inner-Party laws and regulations against corruption should be strengthened and power should be locked in the cage of the system. Then to the Fourth Plenary Session of the Eighteenth Central Committee of the Communist Party of China, as well as the relevant specific the inner-Party laws and regulations have been introduced, making the inner-Party laws and regulations clear its normative expression in concept.

"Regulations on the Establishment of the inner-Party laws and regulations of the Communist Party of China" (hereinafter referred to as the "Regulations") has made detailed provisions on the names, applicable principles, levels and principles of the inner-Party laws and regulations, thus establishing the norma- 
tive status of the inner-Party laws and regulations. "Regulations" (On May 26, 2012) in which the first chapter defines the inner-party regulations as: "A general term of the inner-Party rules and regulations formulated by the central organization of the Party and the central commission for discipline inspection of the CPC, the central departments and the Party committees of provinces, autonomous regions and municipalities directly under the Central Government to regulate the work, activities and conduct of Party members". Although there are many debates on the concept of the inner-Party rules and regulations in the domestic academic circle, most scholars have basically adopted the concept defined in the regulations. However, the concept of the inner-Party rules and regulations in 2012's "Regulations" only clearly shows the formulation subject and content elements, and has not made a detailed description of the essential elements, guarantee implementation and fundamental attributes of the concept. In terms of the content regulated by the regulations within the Party, it is described as the work, activities and behaviors of Party members. It puts the constraint on the behaviors of Party members together with the regulation of the work activities of Party organizations, and defines the fundamental attribute as the rules and regulations within the Party. In fact, there is no obvious difference in connotation and denotation between the inner-Party rules and regulations and the inner-party regulations, which is also the main reason for the debate on the concept of inner-Party regulations in the domestic academic circle.

The "Regulations" revised in 2019 is a normative definition of the inner-Party laws and regulations in the first chapter and the third article, that is, "the inner-Party laws and regulations are special rules and regulations formulated by the Party's central organization, the central commission for discipline inspection of the CPC, the Party's central working organs and the Party committees of provinces, autonomous regions and municipalities directly under the Central Government that reflect the Party's unified will, regulate the Party's leadership and Party building activities, and rely on the Party's disciplinary guarantee". In this standardized concept of party regulations, it can be seen that: firstly, the main elements of the concept are clear. It is helpful to improve the authority and seriousness of inner-Party laws and regulations by restricting the subject of inner-Party laws and regulations to the higher-level party organizations, rather than any level of party organizations, so as to better safeguard the authority and centralized and unified leadership of the Party Central Committee. Secondly, the essential elements of the concept are clear. That is to say, the party regulations reflect the unified will of the party, not the simple addition and compromise of individual party organizations or party members' individual will, nor the individual will of party members and leading cadres. Thirdly, the normative content of the concept is concentrated. That is to say, the objects adjusted by the regulations within the party are the party's leadership and party construction activities, so that the institutional boundary of the regulations within the party can be determined and the extension of the concept can be determined. Adjusting and 
standardizing the party's leadership activities, that is, the role of inner-Party laws and regulations is to realize the institutionalization, legalization and standardization of the leadership of the Communist Party of China, involving the relationship between the party and non-party organizations, including the party and the National People's Congress, the government and even social organizations, involving the scope of the party leading the socialist economy, politics, culture, society and ecological civilization construction with Chinese characteristics. Through the institutionalization and openness of the Party's leadership activities through inner-Party laws and regulations, the Party can be governed by inner-Party laws and regulations, rather than by the will of leading cadres; Adjusting and standardizing the Party building activities is aimed at the relationship within the Party, including the relationship between the Party organizations, the relationship between Party members and the relationship between Party organizations and Party members. Through the construction of the inner-Party laws and regulations system centered on the CPC Constitution, the standardization and legalization of the Party's construction activities are ensured, and the institutional support is provided for improving the construction quality of the CPC.

\section{Attributes and Characteristics of the Inner-Party Laws and Regulations}

The inner-Party laws and regulations system is an important part of the system of socialist rule of law with Chinese characteristics. The inner-Party regulations are laws and also are the special legal norms. Since the definition of the concept of inner-Party laws and regulations is also constantly improved with the development of the practice of the construction of inner-Party laws and regulations, the understanding of the attribute characteristics of inner-Party laws and regulations also shows this trend. Among them, the distinct political attribute is the core, which highlights the uniqueness of party regulations in the socialist legal system with Chinese characteristics. Special normative attribute refers to its general characteristics of legal norms, in the specific operation process is different from national law. The priority attribute of execution means that compared with national law, it has priority applicability in the application of execution. Through the grasp of these three attributes, it can be incorporated into the socialist legal system with Chinese characteristics, and laid the foundation for its cohesion and coordination with national laws.

\section{1) Distinctive political attributes}

Inner-Party laws and regulations, as special rules and regulations for the CPC to govern the Party, regulate the Party's leadership and Party building activities, have distinct political attributes. From the inner-Party laws and regulations related to the important exposition and rich legislative practice, we can clearly see that the inner-Party laws and regulations are the product of party politics, through the establishment of the corresponding system to regulate the behavior of party members and the party itself. It is also the unique political attribute of 
the inner-Party laws and regulations that determines that it can be timely reflected by changes in party policies.

In terms of the specific forms of the inner-Party laws and regulations, As the self-regulation of the Communist Party of China, it is formulated by specific organizations in accordance with specific procedures. The object and scope of its role are aimed at the leadership and construction activities of the Party, involving all kinds of Party organizations at all levels and members of the Party. This clearly shows that the inner-Party laws and regulations are based on the party's political attributes and reflect the party's unified will. From the specific function of the inner-Party laws and regulations, it is in the service of the party's political goal of special regulations, its purpose is to through these special rules and regulations for the leadership of the party and government by law construction standards, is committed to strengthening the construction of the party's long-term ruling ability, advanced nature and purity, the core purpose is to ensure that the communist party of China is always the core of leadership for the cause of socialism with Chinese characteristics. From the aspects of the specific content of the inner-Party laws and regulations and safeguard measures, whether the central party regulations or local regulations, and whether it is a specific adjustment is what kind of relationship or a specific item, clearly reveal the nature of the communist party of China and the principle, guiding ideology, development goal, the basic route and specific policies, is embodies the unity of the communist party of China will. As for the enforcement of the inner-Party laws and regulations, it is the discipline of the Communist Party of China that ensures the implementation, not the other way around. Party discipline not only standardizes specific behaviors through specific punishment measures, but also exerts political guidance and influence of ideology through the political relations between Party organizations and Party members. From the behavior to the thought of the norms, have highlighted a strong political attribute.

\section{2) Special canonical attributes}

As a specific norm, the inner-Party laws and regulations have formed a clear logical and self-consistent normative system, so they are serious normative, or special "legal" attribute. Legal hierarchy refers to a country within the same jurisdiction, because the legal system generally presents crisscross characteristics. In the unitary state structure, in order to maintain the internal unity of the legal system, it requires various legal departments to connect with each other horizontally, and various legal sources to maintain coordination vertically. From the perspective of the effectiveness of law, all sources of law have the formal effectiveness of law, and there is no difference in the effectiveness itself; However, legal norms of different origins have different levels of effectiveness.

With the development of the systematization of the inner-Party laws and regulations, the problem of the rank of the effectiveness of the inner-Party laws and regulations is gradually clarified and standardized. Due to the increasing number of the inner-Party laws and regulations in recent years, it is necessary to solve the problems concerning the application of the effectiveness among the in- 
ner-Party laws and regulations of the CPC Central Committee, the inner-Party laws and regulations of ministries and commissions, local inner-Party laws and regulations as well as the inner-Party laws and regulations formulated by subjects with equal authority. Therefore, the inner-Party laws and regulations, like the national laws, also clarify the issue of the rank of effectiveness, so that the inner-Party laws and regulations have a special "legal" attribute. Specifically, the effectiveness rank of inner-Party laws and regulations is the specific setting to regulate the application of different inner-Party laws and regulations at different levels in the system of inner-Party laws and regulations. The upper-level inner-Party laws and regulations with high effectiveness level are higher than those with low effectiveness level. According to the principle of democratic centralism of the Communist Party of China, adhere to the maintenance of the seriousness and authority of the Party's centralized and unified leadership, subordinate party organizations obey the higher party organizations, each party organization and all-Party members obey the Party Central Committee. Clarifying the effectiveness rank of the inner-Party laws and regulations is conducive to avoiding and resolving potential conflicts within the inner-Party laws and regulations system, and maintaining the unity and authority of the inner-Party laws and regulations system.

\section{3) Priority attributes for execution}

The Party discipline of the Communist Party of China is stricter than the national law, and the inner-Party laws and regulations have strict priority attributes in the implementation and application. Party discipline is stricter than national law, and the national law is a normative system applicable to all citizens and organizations. Therefore, all party members, including Party organizations at all levels, must abide by the Constitution and laws. In a general sense, the law is generally applicable to any organization, including the Communist Party of China, and to any individual, including its members. Due to the particularity of its adjustment object, the inner-Party laws and regulations mainly refer to regulating the Party's leadership and construction activities, and are special rules and regulations for Party organizations at all levels and Party members of the Communist Party of China. Therefore, in the implementation and application of Party regulations, there may be a situation where national laws and Party regulations are regulated simultaneously. Since the inner-party regulations and national laws are the will of the people under the leadership of the party in the fundamental will, there is no absolute conflict in principle. In the implementation and application, especially when there is a violation of national laws and regulations within the party, there is a problem of how to apply, For example, According to Article 29 of the Regulations on Disciplinary Punishment of the Communist Party of China, when dealing with Party member's violation of discipline and law, in principle, Party discipline punishment should be made first, and then government affairs punishment should be given according to the provisions, and then transferred to relevant state organs for handling according to law. In terms of the order in which Party regulations and national laws are ap- 
plied to Party members, the application of Party regulations has a clear priority attribute.

\section{Systematic Construction of the Inner-Party Laws and Regulations}

From the history of the inner-Party legal system construction, its development has gone through the process from individual rules to systematic construction. The goal of the system construction of the inner-Party laws and regulations and the concrete practice construction have made outstanding progress, which is the great achievement of the construction of the inner-Party laws and regulations since the 18th National Congress of the Communist Party of China.

\section{1) Logical construction of the inner-Party laws and regulations system}

We will improve the system of the inner-Party laws and regulations based on the basic framework of " $1+4$ ", that is, under the Party Constitution, it is divided into four sections: the Party's organizational laws and regulations, the Party's leadership laws and regulations, the Party's self-building laws and regulations, and the Party's supervision and guarantee laws and regulations. From the "Opinions on Strengthening the Construction of the inner-Party laws and regulations", a preliminary outline of the inner-Party laws and regulations system of "four beams and eight pillars". "The Outline of the Central Committee's Five-year Plan for the Work of Inner-Party Legislation (2013-2017)", as the CPC's first work plan for the work of the inner-Party laws and regulations, made the systematization and standardization of the inner-Party regulations and systems enter a stage of goal-oriented and orderly work. "The second five year plan for the formulation of the inner-Party laws and regulations within the CPC Central Committee (2018-2022)", focusing on the new era of the new requirements, has been clear about the inner-Party laws and regulations of the construction of the guiding ideology, the goals and objectives and key projects, a new era of the communist party of China party more highlights the systematic construction of the inner-Party laws and regulations and the features of systematic, holistic and collaborative.

Aiming at the specific goal of forming a relatively perfect system of the inner-Party laws and regulations by the time of the 100th anniversary of the founding of the Communist Party of China, in recent years, the progress of formulating and revising the inner-Party laws and regulations has been gradually accelerated. On May 27, 2012, The public release of "Regulations on the Establishment of the inner-Party laws and regulations" and "Provisions on Recording of the inner-Party laws and regulations and Normative Documents of the Communist Party of China" marks the first formal and public party's "legislative law" and filing procedures, It is of great significance to strengthen the legalization, standardization and proceduralization of the construction of the inner-Party laws and regulations, It is of great significance to improve the scientific level of party construction. 
After years of practice in the construction of inner-Party laws and regulations, in order to further improve the quality and implementation of inner-Party laws and regulations, in 2019, the CPC Central Committee revised the "Regulations for the Establishment of the inner-Party laws and regulations" and "Provisions for Recording the inner-Party laws and regulations and Normative Documents" issued in 2012, and formulated "Rule of responsibility". After the introduction of these three inner-Party laws and regulations, together with the regulatory documents issued in recent years such as "Opinions of the Central Committee of the Communist Party of China on Strengthening the Construction of the inner-Party laws and regulations", "Opinions of the General Office of the Central Committee of the Communist Party of China on Cleaning up inner-Party laws and regulations and Normative Documents" and "Regulations on the Interpretation of inner-Party laws and regulations", The whole chain of institutional norms on the work of the inner-Party laws and regulations has strongly promoted the systematic construction of the inner-Party laws and regulations.

2) The continuous improvement of the inner-Party laws and regulations system

In the process of promoting the systematic construction of inner-Party laws and regulations, the Communist Party of China has always adhered to the combination of goal orientation and problem. In the field of the Party's leadership and construction, it is necessary to continuously strengthen the work of formulating new regulations and systems within the Party, and to make up for the shortcomings and deficiencies in the institutional framework, so that the main areas of the Party's life have basically realized the rule of law, and provided the rule of law guarantee and basic system compliance for all aspects of the Party's work.

From the Central Committee of the Communist Party of China to the local party regulations at all levels of the main body for the specific supporting inner-Party laws and regulations made a detailed and specific system design. In addition, in view of the Communist Party of China nearly a hundred years of inner-Party laws and regulations system construction history, the long-term application or no longer suitable for the new situation to continue to apply some of inner-Party laws and regulations, timely revision and clean-up, to ensure the scientific level of the system construction of inner-Party laws and regulations.

In the Clean-up of inner-Party laws and regulations, June 2012, the Central Committee of the Communist Party of China approved the issuance of the "Opinions of the General Office of the Central Committee of the Communist Party of China on Cleaning up inner-Party laws and regulations and Normative Documents", which made it clear that the clean-up of inner-Party laws and regulations was carried out in two stages. This centralized clean-up of inner-Party laws and regulations and normative documents is the first time in the history of the Communist Party of China, and is a basic project for the legalization and standardization of the party's system construction. Through this clean-up work, rich experience has been accumulated for regular clean-up of normalized in- 
ner-Party laws and regulations. Centralized clean-up also helps to improve the execution of inner-Party laws and regulations and effectively avoid the "Broken Windows". In April 2019, "Decision of the Central Committee of the Communist Party of China on Abolishing, Declaring Failure and Amending Some inner-Party laws and regulations and Normative Documents" was released. The release of the "Decision" marks the successful completion of the second centralized clean-up of central inner-Party laws and regulations and normative documents. The Central Committee of the Communist Party of China decided to make a package of amendments to the central inner-Party laws and regulations and normative documents included in the scope of liquidation, including 54 repealed, 56 declared invalid, and 8 revised. At the same time, it made a package of amendments to 14 central party regulations related to the reform of the party and state institutions. The work of clearing up inner-Party laws and regulations around the systematic construction of inner-Party laws and regulations has formed specific working methods of centralized cleaning, special cleaning and immediate cleaning. In addition, in the process of establishing and perfecting the inner-Party laws and regulations system, taking the organizational laws and regulations of the Communist Party of China as an example, 201 party organizations and regulations were issued in 2019, including 4 central inner-Party laws and regulations and regulations, 5 ministries inner-Party laws and regulations, 192 local inner-Party laws and regulations (Jiang, 2020).

In summary, the inner-party legal system and the socialist legal system are both important components of the socialist legal system with Chinese characteristics. The Communist Party of China has also made outstanding achievements in promoting the systematic construction of the inner-party legal system. However, since there are many complex relationships between the inner-party laws and regulations and national laws, in order to better promote the construction level of the inner-party laws and regulations system, it is necessary to pay attention to the cohesion and coordination between the two, so the next section will focus on this issue.

\section{Connecting and Coordinating Inner-Party Laws and Regulations with the National Laws}

The inner-Party laws and regulations, national laws and social norms together constitute the institutional basis of "Chinese system" and "Chinese governance". The People's Republic of China is a country led and ruled by the Communist Party of China for a long time. The Party regulations are formulated by the CPC and the state laws are formulated under the leadership of the CPC. This fundamentally determines that the Party regulations and state laws are necessarily unified in nature and both reflect the will of the Party and the people. The system of inner-Party laws and regulations with inner-Party laws and regulations as the main body, the system of legal norms with national laws as the main body, the system of legal implementation, the system of legal supervision and the system of legal guarantee jointly constitute the socialist legal system with Chinese cha- 
racteristics. Therefore, inner-Party laws and regulations with the national laws belong to two different categories.

\section{1) Differences between Party regulations and national laws}

First, the subjects and procedures of the two are significantly different. The main body of the inner-Party laws and regulations is embodied in the central organization of the CPC, the Central Commission for Discipline Inspection, the working organs of the CPC Central Committee and the Party committees of provinces, autonomous regions and municipalities directly under the Central Government. The main body of the formulation of national laws is the state-specific legislature under the leadership of the Communist Party of China, which is embodied as a state organ with statutory legislative power endowed by the Constitution or law. It can be clearly seen that the difference between the two, the former is mainly concentrated in the party's organizations at all levels, and the latter is mainly concentrated in the people's congresses and government organs at all levels. In the formulation of procedures, the inner party regulations should adhere to the party constitution as the fundamental follow, according to the relevant provisions of "Constitution of the Communist Party of China", "Regulations on the Establishment of Party Regulations of the Communist Party of China"; The National laws adhere to the constitution as the fundamental follow, according to "Constitution", "Legislative law" and other relevant provisions.

Second, the embodied will and application scope of the two are different. The inner-Party laws and regulations, as an important carrier of the Communist Party of China governing the Party, comprehensively and strictly governing the Party and realizing the institutionalization, legalization and standardization of the Party's leadership, embody the unified will of the Communist Party of China. The scope of its application is also limited to the leadership of the Communist Party of China and party building activities, specific to the party organizations and party members at all levels and other related subjects. The national law reflects the national will of the ruling class, and China is the will of the people under the leadership of the Communist Party of China. Its scope of application is the state organs and armed forces, political parties and social groups, enterprises and institutions organizations and citizens (Song \& Zhang, 2020). It is obvious that the objects of application of the aforementioned inner-Party laws and regulations should also operate within the scope of the Constitution and laws, and no organization or citizen has the privilege to violate the Constitution and laws.

Third, the authority of the implementation of the two safeguards is different. According to the "Regulations on the Establishment of inner-Party laws and regulations", the laws and regulations within the Party are implemented by the Party's discipline. It is specifically under the centralized and unified leadership of the Party Central Committee to establish and improve the unified leadership of the Party Committee, the overall coordination of the offices of the Party Committee, the responsibility of the competent authorities, and the assistance and cooperation of relevant units, and strictly supervised by the Party's discip- 
line inspection authorities. And the implementation of various types of inner-party laws and regulations in the system of clear, can be said that the authority of the implementation of inner-Party laws and regulations has a very strict system design. However, the national law is by the national coercive force guarantees the implementation, has the universal binding force to the whole society member. From the implementation of the constitution at the highest level to the implementation of the basic national laws, administrative rules and local regulations, there are specific implementation methods and principles.

2) Coherence and coordination of the inner-Party laws and regulations and national laws

There is an inherent unity between the inner-Party laws and regulations and the national laws. Both of them reflect the consistency of the Party's unified will, the people's will and the national will in essence and value. Although there are differences in the scope of their role and the way of ensuring implementation, they adhere to the leadership of the Communist Party of China and adhere to the people-centered core position. The national governance system of socialism with Chinese characteristics is originally constructed by a set of systems, in which the inner-Party laws and regulations with the party constitution as the fundamental follow and the national legal system with the constitution as the guidance are indispensable basic institutional systems. The two institutional systems jointly provide institutional guarantee for promoting the modernization of national governance system and governance capacity. In terms of organic connection and coordination between inner-Party laws and regulations and national laws, the following points should be noted:

First, the system construction of inner-Party laws and regulations should strengthen the scientific nature of top-level design to prevent excessive spillover of inner-Party laws and regulations. Realize the coordination of the two under the socialist legal system with Chinese characteristics. In other words, the scope of application belonging to the inner-Party laws and regulations system should have clear boundaries, and some scholars in the academic circle have also noticed the so-called "Spillover Effect" (Hou, 2019). Obviously, the inner-Party laws and regulations are mainly adjusted by party organizations and party members, but under the socialist political system with Chinese characteristics, the leadership of the Communist Party of China is the essential feature of socialism. Therefore, regulating the party's leadership and party building activities reflect the party's unified will of the inner-Party laws and regulations, based on the leadership of the Communist Party of China, must have an indirect effect and influence with the masses outside the party and non-party organizations. This influence actually exists. The Communist Party of China leads the people to govern the country through the formulation of guidelines and policies, and converts the will of the people under the leadership of the Communist Party of China into the will of the state through the form of national laws. Therefore, under the principle of adhering to the independence of the inner-Party laws and regulations system and the normative principle of the national legal system, the 
scientificity of the top-level design should be strengthened to prevent the excessive spillover of the inner-Party laws and regulations and avoid the tendency to replace the national law with the inner-Party laws and regulations.

Second, we should build a normative mechanism for the discourse conversion between the inner-Party laws and regulations and national laws, so as to realize the effective connection between the two systems. In other words, certain norms in the inner-Party laws and regulations can provide resources for national laws; Relevant contents in national laws can also provide support for the institutional development of the inner-Party laws and regulations. From the current system of the inner-Party laws and regulations which takes the party constitution as the core and the national legal system which takes the constitution as the core, there exists the phenomenon of intercommunication and interconnection between the two. Taking the Party Constitution and Constitution as an example, the relevant provisions in the Party Constitution of the Communist Party of China have been recognized by the Constitution and laws and have been turned into components of the Constitution and laws. Party leadership is the essential feature of socialism. The Party Constitution stipulates the general contents of the Party's nature, guiding ideology, program and tasks, major lines, principles and policies, as well as the specific contents of the Party's organizational structure and system, as well as the qualifications, rights, obligations, and discipline of Party members. It is the purpose and code of conduct of a political party. Its core content is often reflected in various forms in the constitution, the fundamental law. Focusing on the fight against corruption requires the concerted efforts of the inner-Party laws and regulations and national laws. To realize the effective connection between the party disciplinary punishment and the government disciplinary punishment is helpful to fundamentally build a centralized, unified, authoritative and efficient anti-corruption system and enhance the effectiveness of anti-corruption governance. Specialized government affairs punishment legislation will enhance the strength of the coordination of discipline and law, and contribute to the construction of clean government. In the application of evidence, the determination of proof standards and the transformation of evidence, we can further improve the effectiveness of the two punishments in the connection of procedures. Under the rule of law thinking, optimizing the object and weight connection between the party discipline punishment and government affairs punishment is conducive to the construction of the punishment mechanism with clear rights and responsibilities and benign operation (Qin \& Zhou, 2021).

In conclusion, the research on the normative concept of inner-party laws and regulations has laid a solid foundation for the construction and development of the discipline of inner-party laws and regulations. The analysis of the inner attributes of inner-party laws and regulations, especially its political attributes, normative attributes and priority attributes, can distinguish it from national laws, and then clarify the independence character of inner-party laws and regulations. With the continuous introduction of inner-party laws and regulations, it is necessary to strengthen the system of inner-party laws and regulations, and do 
a good job in the process of cohesion and coordination between inner-party laws and regulations and national laws.

\section{Conclusion}

The inner-Party laws and regulations system is an important part of the system of socialist rule of law with Chinese characteristics, it is bound to the basis of the connotation and denotation of "legal" theory put forward the challenge, and how to fully embody the socialist rule of law theory with Chinese characteristics, Chinese style, Chinese style, discourse system and the socialist rule of law theory on how to maturity, etc., need further research. In addition, in terms of the inner-Party laws and regulations construction practice, how to ensure the system of the organic unity of quantity and quality, especially in the concrete execution and apply, how to do the coordination between the inner-Party laws and regulations and state laws and do early strict discipline on the national laws, ensure the implementation of national laws, etc., should be in the study of specific issues more elaborate concrete system operation.

1) Firmly adhere to the ideological guidance of the theory of socialist rule of law with Chinese characteristics

We should firmly adhere to the ideological guidance of the theory of socialist rule of law with Chinese characteristics, deepen the theoretical research consensus on the construction of the inner-Party laws and regulations, and then enrich and develop the theory of socialist rule of law with Chinese characteristics. The importance of the inner-Party laws and regulations in building a socialist country under the rule of law with Chinese characteristics is not only the nature of socialism as stipulated in the Constitution, but also an inevitable requirement of CPC leadership under the comprehensive and strict governance of the Party. It is also an important support for the Party's long-term governance and its legitimacy.

First, the inner-Party laws and regulations system and the legal system of socialism with Chinese characteristics is the same position, and each as a subsystem, constitute the rule of law system of socialism with Chinese characteristics of this system. The inner-Party laws and regulations must realize the systematization of form and content, become an open independent autonomous system, can operate independently, and play its due function and role. The cohesion and coordination between the regulation system of the Communist Party of China and the legal system of socialism with Chinese characteristics should be done in the large system. The inner-Party laws and regulations system and the national legal system are juxtaposed, and the norms of the inner-Party laws and regulations system cannot be equated with the laws of various departments.

Second, the function of inner-Party laws and regulations is a combination of political attributes and legal attributes, political attributes priority, more about obligations rather than rights. The biggest difference between the inner-Party laws and regulations and the national laws is that the national laws, as the carrier 
of citizens' behavior norms, can only be a set of rules that restrict citizens' specific behavior. Obviously, the inner-Party laws and regulations are not only here, but also more importantly, the inner-Party laws and regulations should restrict the ideological problems of the Party's organizations and members at all levels. Grasping the attributes of inner-Party laws and regulations of the Communist Party of China must be based on a deep understanding of the dialectical and unified relationship between politics and law, politics and the rule of law, and should adhere to the principle of the unity of governing the country according to law, governing the party by system and governing the party according to rules.

2) Effectively improve the implementation of inner-Party laws and regulations under the rule of law

The essence of socialism with Chinese characteristics lies in the leadership of the Communist Party of China. To successfully realize the modernization of Chinese national governance system and governance capacity, it is necessary to realize the institutionalization and legalization of the leadership of the Communist Party of China. With the legislative process of the inner-Party laws and regulations at all levels and all kinds of norms, the number will be explosive growth, so the quality of legislation should be guaranteed to keep up with.

First, strengthen the Cleanup of inner-Party laws and regulations and the Quality of Legislation. Since the 18th National Congress of the Communist Party of China, the Six adherences formed around the practice of inner-party legal system construction are the basic principles of inner-Party laws and regulations system construction. During the second five-year planning and construction of the inner-Party laws and regulations legislation, we should adhere to the uncoordinated and mismatched clean-up review of the existing inner-Party laws and regulations system, and avoid duplication of legislation. In the formulation of the new law, we should pay attention to the prevention of institutional gaps and institutional surplus, adhere to meet the needs of comprehensively and strictly administering the party, and complement the shortcomings of the inner-Party laws and regulations system. To coordinate the leadership and construction of the Communist Party of China in all aspects of the legal system, all levels of laws and regulations are clear and organized, substantive, procedural and security laws and regulations are matched, and improve the level of interpretation and filing of laws and regulations within the party, effectively forming the overall effect of the implementation of the rule of law of the party's laws and regulations.

Second, strengthen the implementation of the inner-Party laws and regulations, the life of the law lies in the implementation, especially the laws and regulations within the party. The authority of the inner-Party laws and regulations should be reflected in the concrete implementation and implementation. The procedural guarantee of the inner-Party laws and regulations system is the key task. Only by firmly grasping the institutional advantages brought by improving the implementation of inner-Party laws and regulations and making the in- 
ner-Party laws and regulations run under the rule of law, can it be effectively transformed into the actual effectiveness of the party's leadership in realizing the rule of law within the party. By grasping the key minority of leading cadres and paying close attention to the implementation of the system, we can effectively improve the Party members and cadres' awareness of discipline compliance, and then enhance the Party's leadership and ruling ability. In addition, it is necessary to carry out scientific and effective evaluation in the whole process of the implementation of inner-Party laws and regulations.

\section{Fund Project}

Research on the Function and Practice of Inner-Party Regulations of the Communist Party of China (Project No.: C2-2020114); Shanghai Social Science Planning General Project "Research on the Basic Experience of the Construction of Inner-Party Laws and Regulations since the 18th CPC National Congress" (Project No.: 2020BKS009).

\section{Conflicts of Interest}

The author declares no conflicts of interest regarding the publication of this paper.

\section{References}

Hou, J. B. (2019). The Definition and Justifications of the Spillover Effect of Inner-Party Laws and Regulations. Theoretical Research of Party Laws and Regulations, No. 2, $2-17$.

Jiang, B. X. (Ed.) (2020). Report on the Implementation of the Rule of Law in China. Beijing: People's Court Press.

Jiang, M. A. (2012). On the Nature and Function of the Party Regulations of the Communist Party of China. Journal of Peking University (Philosophy and Social Sciences Edition), No. 3, 109-120.

Qin, Q. H., \& Zhou, H. (2021). The Coordination and Operation Mechanism of Party Discipline and Government Discipline. China Law Review, No. 1, 167-178.

Song, G. D., \& Zhang, W. X. (2020). Inner-Party Law (p. 22). Beijing: Higher Education Press.

Wu, X. C. (2016). Power Restriction Theory of "Inner-Party Laws and Regulations" and the Application Limitation of "Inner-Party Laws and Regulations" Soft Law Theory. Journal of CPC Central Party School, No. 6, 14-23.

Xiao, J. M., \& Feng, X. C. (2019). The Orientation of Inner-Party Laws and Regulations from the Perspective of Governance Modernization. Journal of Sichuan Normal University (Social Science Edition), No. 1, 95-103. 